\title{
Los Delitos de Incontinencia en los Manuales de Medicina Legal del Médico Luis Hidalgo y Carpio a Finales del Siglo XIX en México
}

\author{
Graciela Velázquez, PhD \\ Departamento de Historia, Universidad de Guanajuato, México
}

\section{Resumen}

Este artículo tiene como objetivo analizar los delitos de incontinencia en la medicina legal a través de los dos manuales que fueron escritos por el médico Luis Hidalgo y Carpio, con la intención de examinar hasta qué punto ésta no solamente transmitió conocimientos científicamente establecidos, sino también creencias culturales de la época que estuvieron presentes en la práctica médica. Para lograr este análisis es importante, en primer lugar, realizar una indagación sobre el desarrollo de la medicina legal, para mostrar cómo se institucionalizó y consolidó como auxiliar en la administración de justicia en México. A continuación, se indaga sobre los delitos de incontinencia a través de los manuales del médico Luis Hidalgo y Carpio, a saber: Introducción al estudio de la medicina legal, publicado en 1869, y junto a Gustavo Ruíz y Sandoval, Compendio de medicina legal de 1877, con el objetivo de mostrar la forma en que eran pensados no sólo por éste médico, sino que sus ideas obedecían a una influencia científica, pero también cultural.

Palabras clave: Estupro, Violación, Sodomía, Medicina legal, Ciencia, Luis Hidalgo y Carpio 


\title{
The Crimes of Incontinence in the Manuals of Legal Medicine by Doctor Luis Hidalgo y Carpio at the End of the Nineteen Century in Mexico
}

\author{
Graciela Velázquez, PhD \\ Departamento de Historia, Universidad de Guanajuato, México
}

\begin{abstract}
This paper focuses on analyzing the crimes of incontinence in legal medicine through the two manuals that were written by Doctor Luis Hidalgo and Carpio. This is with the intention of examining the extent by which scientifically-established knowledge is not only transmitted, but also cultural beliefs that were present in practice at that time. To achieve this analysis, it is important, first, to conduct an investigation on the development of legal medicine. This would help to show how it was institutionalized and consolidated as an assistant in the administration of justice in Mexico. After then, the crimes of incontinence will be investigated using the manuals of Doctor Luis Hidalgo y Carpio, namely: Introducción al estudio de la medicina legal, published in 1869, and together with Gustavo Ruíz y Sandoval, Compendio de medicina legal of 1877. This point to the fact that they were not only taught by this doctor, but his ideas agreed with both scientific and cultural influence.
\end{abstract}

Keywords: Rape, Sexual violation, Sodomy, Legal medicine, Hidalgo and Carpio

\section{Introducción}

Como asegura Ana Flisser (2009), durante el siglo XIX las ciencias médicas enfrentaron varios retos para lograr su consolidación; entre otros, se inició una transformación de estas como actividades experimentales y se establecieron las especialidades médicas (p. 353) para profesionalizar a los médicos y distanciarse de los charlatanes que se ostentaban como tales. Como base de estos cambios se le dio una gran importancia a la anatomía y se abandonó el concepto humoral de las funciones y de las enfermedades. A partir de este momento, la clínica y la anatomía dirigieron la investigación y la práctica de la medicina.

Para todas las especialidades que se fueron creando en la medicina se comenzaron a realizar y publicar libros de texto y manuales para desarrollar la 
práctica. Estos manuales, libros de texto o ejemplares (como los llama Thomas S. Kuhn), son aquellos documentos que gozan de autoridad epistémica en alguna disciplina, en los que se localiza el cuerpo de conocimientos de los que dispone cada una de las ciencias, y por medio de ellos se transmite su contenido cognoscitivo y se alcanza su aprendizaje, de tal manera que "el adquirir un arsenal de ejemplares, así como aprender generalizaciones simbólicas, es intrínseco al proceso por el que un estudiante alcanza el acceso a los logros cognitivos de su grupo disciplinar" (Kuhn, 1979, p.521). Por lo tanto, para determinar la enseñanza que se les impartía a los médicos con respecto a la medicina legal, es necesario examinar sus textos que funcionaron como orientadores didácticos, no sólo con el objetivo de dilucidar sus aportes científicos sino todos aquellos valores extra-científicos que contenían, y que estuvieron presentes en la práctica científica, pues, no obstante la confianza que se otorgaba a la medicina legal como disciplina académica para desentrañar los casos penales, los manuales utilizados para la enseñanza y la consulta por parte de los médicos en su práctica no estaban exentos de creencias culturales y morales acerca de dichos delitos de incontinencia.

Los actos de incontinencia eran considerados por el cristianismo como pecados en tanto acciones que iban en contra de lo que se aceptaba como voluntad de Dios y, dentro de sociedades tan penetradas de religión como las occidentales del siglo XIX, estos a la larga habían ido conceptuándose como delitos dentro de sus códigos penales. Según Joaquín Escriche, en su Diccionario razonado de Legislación y jurisprudencia (1863), los actos de incontinencia eran: "el amancebamiento o concubinato, la bigamia o poligamia, el estupro, el incesto, el lenocinio, el rapto, la sodomía o pederastia y la bestialidad" (p. 847). Aunque los delitos de incontinencia que menciona este autor son muchos, Hidalgo y Carpio solamente se ocupará en México de la sodomía, el estupro y la violación, porque únicamente en estos casos dicha especialidad médica podía determinar por sus efectos los actos cometidos en el cuerpo humano y relacionarlos con tales delitos.

Así pues, este artículo tiene como objetivo analizar los delitos de incontinencia como la sodomía, el estupro y la violación en la medicina legal a través de los dos manuales que fueron escritos por el médico Luis Hidalgo y Carpio, y esto se hará con la intención de examinar hasta qué punto ésta no solamente transmitió conocimientos científicamente establecidos, sino también creencias culturales que estuvieron presentes en la práctica médica y legal de la época. Para lograr este análisis es importante, en primer lugar, realizar una indagación sobre el desarrollo de la medicina legal, para mostrar cómo se institucionalizó y consolidó como auxiliar en la administración de justicia en México. En consecuencia, se indaga sobre los delitos de incontinencia a través de los manuales del médico Luis Hidalgo y Carpio, a saber: Introducción al estudio de la medicina legal, publicado en 1869, y junto 
a Gustavo Ruíz y Sandoval, Compendio de medicina legal de 1877, con el objetivo de mostrar la forma en que eran pensados no sólo por éste médico y su colega, sino que sus ideas obedecían a una formación científica, pero también cultural y moral, entendiendo la moral como lo plantea Foucault (2007) como el conjunto de valores y normas socialmente aceptables que son transmitidos a los individuos o a los grupos a través de instituciones sociales como la familia, las escuelas y la iglesia (Foucault en Márquez Estrada, 2013, p.35).

\section{El desarrollo de la medicina legal en la Escuela Nacional de Medicina}

La medicina legal se consolidó entre el siglo XVIII y el XIX favorecida por el cada vez mayor estatus de cientificidad de la medicina en general. En Francia, a partir de 1794, se crearon cátedras de medicina legal en las escuelas de medicina, así como instituciones relacionadas con ella como el Laboratorio de Toxicología (1868), la Sociedad de Medicina Legal de París (1868) y el servicio de "Identidad judicial" (1893) que estuvo a cargo de Alphonse Bertillon (Watson, 2011, p.52). Por otro lado, se publicaron varios tratados sobre la materia, como el Traité de médecine légale et d'hygiène publique ou de police de santé (1813) de François-Emmanuel Fodéré (1764-1833); Leçons de médecine légale (1823) de Mateo Orfila (1787-1853); así como el Traité de Medicine Légale, de jurisprudence médicale et de toxicologie (1874) de Henri Legrand du Saulle (1830-1886), entre otros. Dichos tratados eran utilizados por los estudiantes de medicina en las universidades francesas, pues sus autores fueron prestigiosos catedráticos en ellas.

En México, debido a la inestabilidad política y económica de la primera mitad del siglo XIX, la medicina tuvo varios contratiempos para desarrollar su enseñanza y su práctica. Después de la independencia se inició una reforma educativa con la intención de desaparecer la herencia colonial en las instituciones nacionales, es por eso, que el 19 de octubre de 1833, en el gobierno de Antonio López de Santa Anna, su vicepresidente Valentín Gómez Farías promulgó leyes para suprimir la Universidad de México y, al mismo tiempo, se instituyó la Dirección General de Instrucción Pública, para coordinar y desarrollar la educación nacional en todos sus niveles (Rodríguez, 2008, p.19). Posteriormente, el 23 de octubre de ese mismo año, se creó el Establecimiento de Ciencias Médicas, que más tarde, en 1842 dio paso a la Escuela de Medicina, y en 1854 se convirtió en Escuela Nacional de Medicina (Carrillo \& Saldaña, 2005, p.257).

Los cambios de nombre de la institución también fueron acompañados de reformas curriculares. En 1833 se realizó un plan de estudios de la carrera de medicina, en el cual se unificaron la medicina y la cirugía para que el título fuera de médico-cirujano. Las materias que contenía este plan de estudios eran 
las siguientes: Anatomía general, descriptiva y patológica; Prosector de anatomía; Fisiología e higiene; Patología externa; Patología interna; Operaciones y obstetricia; Farmacia teórico-práctica; Materia médica; Medicina legal; Clínica externa y Clínica interna (Rodríguez, 2008, p.73-74). En esta currícula aparecía la medicina legal como una materia que tenía que ser cursada por los estudiantes de medicina, y así lo constatan también los diferentes planes de estudio que se siguieron durante el siglo XIX.

Martha Eugenia Rodríguez (2008) menciona que "en el decreto del 23 de octubre de 1833 se señalaba que correspondía a la Junta Directiva de Instrucción Pública elegir los textos que debían leer los alumnos. Al año siguiente, a través del plan de estudios del 12 de noviembre de 1834 se ordenó que el director y los catedráticos de cada escuela los asignaran” (p. 88). En la siguiente tabla se muestran los diferentes planes de estudios, los profesores que impartieron la materia de medicina legal y los textos que fueron sugeridos para este curso a lo largo del siglo XIX. ${ }^{1}$

\begin{tabular}{|l|l|l|}
\hline $\begin{array}{l}\text { Plan } \\
\text { estudios }\end{array}$ & Profesor & Texto \\
\hline 1833 & Agustín Arellano & $\begin{array}{l}\text { Joseph Braind, Manuel complet de médicine légale, } \\
\text { París, 1828. }\end{array}$ \\
\hline 1835 & En este plan se suprimió la medicina legal \\
\hline 1839 & Casimiro Liceaga & Sin texto \\
\hline 1846 & Casimiro Liceaga & $\begin{array}{l}\text { Henri-Louis Bayard, De la necesité des études } \\
\text { pratiques en médicine légale, París, 1840. }\end{array}$ \\
\hline 1855 & José Ignacio Durán & $\begin{array}{l}\text { Pedro Mata, Tratado de medicina y cirugía legal, } \\
\text { Madrid, 1846. }\end{array}$ \\
\hline 1862 & José Ignacio Durán & $\begin{array}{l}\text { Joseph Braind, Manuel complet de médicine légale, } \\
\text { París. }\end{array}$ \\
\hline 1868 & Luis Hidalgo y Carpio & $\begin{array}{l}\text { John Ludwig Casper, Traité pratique de médicine } \\
\text { légale, París, 1862. }\end{array}$ \\
\hline 1874 & Agustín Andrade & $\begin{array}{l}\text { Joseph Braind y Ernest Chaude, Manuel complet de } \\
\text { médicine légale, París, 1869. } \\
\text { Luis Hidalgo y Carpio, Introducción al estudio de la } \\
\text { medicina legal mexicana, México, 1869. }\end{array}$ \\
\hline 1886 & $\begin{array}{l}\text { A.B. Paulier y Frédéric Hetel, Traité élémentaire de } \\
\text { médicine légale, de jurisprudence medicale et de } \\
\text { toxicologie, París, 1881. }\end{array}$ \\
\hline
\end{tabular}

Como puede observarse, con excepción de los planes de estudio de 1835 y 1839 , en todos los demás, se recomendaron textos de medicina legal, de autores europeos, franceses, alemanes y españoles como Joseph Braind, Henri-Louis Bayard, John Ludwig Casper, Joseph Briand y Ernest Chaude, Armand B. Paulier y Frédéric Hetel y Pedro Mata, que aparece en de 1855, mientras que en el de 1874 se recomendó el texto del mexicano Luis Hidalgo y Carpio, que había sido publicado cinco años antes, en 1869.

\footnotetext{
${ }^{1}$ El cuadro es un resumen de los planes de estudio que se llevaron en la carrera de medicina a lo
} largo del siglo XIX. Tomado de Rodríguez (2008). 
Este médico nació en Puebla el 18 de marzo de 1818. Su familia fue de muy escasos recursos económicos y muy religiosa. Se casó en tres ocasiones y tuvo una familia muy numerosa. Sus estudios los realizó en el Seminario Conciliar de su ciudad natal. En 1838 se matriculó en el Colegio de Medicina de la ciudad de México, en 1839 estudió botánica y en 1843 se tituló como médico cirujano. Fue parte del Consejo Superior de Salubridad, así como de varias sociedades académicas de la ciudad de México, Puebla, Mérida, Toluca y Guanajuato. Como docente estuvo como adjunto en la Escuela Nacional de Medicina en 1843, en la cual impartió las asignaturas de Patología, Farmacología, Fisiología, Clínica externa y Medicina legal (Rodríguez, 2009, p.161). A partir de 1845 dio temporalmente el curso de medicina legal en la Escuela de Medicina, después de que el médico Casimiro Liceaga se ausentara de la cátedra. En ese mismo año, ingresó al Cuerpo Médico Militar como cirujano, y en 1847 se unió a las fuerzas armadas para combatir al ejército estadounidense. En 1868 volvió a impartir el curso de Medicina Legal cuando el doctor José Ignacio Durán falleció. Seis años más tarde, renunció a esta institución por diferencias ideológicas, específicamente porque no estaba de acuerdo con las Leyes de Reforma, pues él era sumamente religioso (Rodríguez, 2009, p.161). En la Escuela Nacional de Medicina se desempeñó como docente y editor de la Revista la Gaceta Médica de México. Además de lo anterior, en 1869 participó en la comisión para formular el Código Penal de la ciudad de México. Falleció en esa ciudad el 12 de mayo de 1879 (Rodríguez, 2009, p.162).

En cuanto a su actividad, este médico ejerció una notable influencia en la consolidación de la medicina legal pues, por un lado, impartió cursos sobre esta especialidad y esto permitió que formara a algunas generaciones de estudiantes de medicina; además, también fue un referente en la materia, pues sus libros se usaron para la enseñanza de los médicos que realizaban su práctica auxiliando en los tribunales. Participó en la elaboración del Código penal para el Distrito Federal y Territorio de la Baja California sobre delitos del fuero común, y para toda la República sobre delitos contra la Federación, promulgado en 1871, y en este se normó y legitimó la participación de los médicos legistas en las tareas de la procuración, administración e impartición de justicia. Dicha labor era de tipo probatorio en los juicios penales de los tribunales y los conocimientos médicos fueron herramientas indispensables en ellos para determinar no solamente el delito, sino incluso al autor de éste.

Ahora bien, el libro de Hidalgo y Carpio Introducción al estudio de la medicina legal, publicado en 1869, fue utilizado como libro de texto de la Escuela Nacional de Medicina para desarrollar la docencia de la cátedra de medicina legal. Posteriormente, junto a Gustavo Ruíz y Sandoval, en 1877 publicó su obra Compendio de medicina legal, que tuvo la pretensión de servir como apoyo y orientación didáctica para la práctica de los médicos legistas en 
los tribunales, pues para cuando se publicó ya no fungía como profesor de la institución médica (Rodríguez, 2009, p.162).

\section{Los delitos de incontinencia en los manuales de medicina legal de Luis Hidalgo y Carpio}

En Introducción al estudio de la medicina legal (1869) Hidalgo y Carpio menciona que antes de su texto se había publicado el libro del Licenciado Don Rafael Roa Bárcena (1832-1863) titulado Manual razonado de práctica criminal y Médico-legal forense mexicana (1860), que constaba de cuatro libros: el primero de los cuales trataba sobre las leyes penales vigentes en México; el segundo, contenía la clasificación de los delitos; el tercero se ocupaba de los juicios criminales; y el cuarto y último, versaba sobre los recursos extraordinarios como el indulto y el asilo que tenían lugar en los juicios criminales (p. VIII-X).

Aunque el doctor Hidalgo consideraba que la obra de Roa era importante, creía también que tenía grandes vacíos, en parte, porque había sido pensada para diferentes lectores y practicantes que los de Hidalgo. La de Roa Bárcena se había escrito para los abogados y no para los médicos, mientras que la del doctor Hidalgo y Carpio estaba destinada para que los médicos tuvieran una herramienta en la cual basaran su práctica en los tribunales. Incluso, el doctor Hidalgo y Carpio en Introducción (1869) dice al final del prólogo que: "QQuiera el cielo que este fruto de una parte de mis estudios y meditaciones, sea de alguna utilidad a los estudiantes de medicina de México!" (p.V). Ahí mismo asegura que "He creído útil publicar este opúsculo que sirva de introducción al estudio de la Medicina Legal Mexicana, no habiendo otro publicado en México que abrace estos diversos objetos" (p. IV).

El libro de Introducción (1869) se publicó antes de la promulgación del Código penal para el Distrito Federal y Territorio de la Baja California sobre delitos del fuero común, y para toda la República sobre delitos contra la Federación (1871), mientras que el Compendio fue editado en 1877 cuando ya estaba en vigor dicho código, así que éste último ya tiene contenidos que lo refieren directamente. Los delitos de incontinencia Escriche (1863) los definió como: "el abuso de los placeres sensuales y toda clase de unión ilegítima entre personas de diverso sexo", a los cuales clasificaba como 1.- amancebamiento o concubinato, 2.- bigamia o poligamia, 3.- estupro, 4.- incesto, 5.- lenocinio, 6.- rapto, 7.- sodomía o pederastia y 9.- bestialidad (p. 847). Estos actos eran considerados en los códigos penales como ultrajes a la moral y las buenas costumbres, pues herían a las familias cuando se efectuaban y cuando algunos de ellos se realizaban públicamente y, por lo tanto, tenían que ser sancionados. Y para la sanción, los jueces eran auxiliados por los peritajes médicos que se realizaban en el cuerpo de la víctima. De todos los delitos mencionados en la definición de incontinencia por Escriche, Hidalgo y Carpio analizó en sus 
obras como susceptibles de ser verificados por la medicina legal, los ultrajes a la moral y las buenas costumbres como algunos actos impúdicos y la sodomía, y atentados contra el pudor como el estupro y la violación.

Por supuesto, estos delitos eran considerados de esta manera porque la mentalidad de los legisladores y jueces estaba muy ligada con las consideraciones religiosas de la época, en la cual se establecían como desviaciones a la moral, porque solamente era aceptable que las relaciones fueran heterosexuales con fines de procreación; por lo tanto, todo aquello que no tuviera dicha finalidad era considerado como un ultraje a las buenas costumbres y a la moral o al pudor.

Cabe mencionar que los libros de Hidalgo y Carpio fueron publicados en un momento en el que el país había consolidado la separación de la Iglesia y el Estado por medio de la Constitución de 1857. Sin embargo, a pesar de que la constitución había sido tajante con respecto a la injerencia de la Iglesia en los asuntos públicos del Estado, la sociedad seguía siendo mayoritariamente católica. Por lo tanto, no es de extrañar que las creencias religiosas con respecto a la moral siguieran presentes en los diferentes códigos civiles y penales (Sáenz \& Arcadio, 2018), así como en los manuales científicos, incluyendo los del personaje que ahora nos ocupa.

En el libro del Compendio (1877), los delitos de incontinencia son tratados en el capítulo I, y en su artículo I dedicado a los ultrajes a la moral pública o a las buenas costumbres, se incluyeron reflexiones sobre algunos actos impúdicos y la sodomía, mientras que en los atentados contra el pudor se consideró al estupro y la violación. A continuación veremos el análisis de cada uno de ellos.

a) De ciertos actos impúdicos

Los actos impúdicos eran aquellos que se consideraban carentes de pudor o recato, particularmente los que implicaban la exhibición o el tocamiento de los genitales en público, y que por lo mismo ofendían y escandalizaban a la sociedad hasta el grado de ser considerados como delitos.

Sin embargo, en términos de la medicina legal, una parte de estos actos podían deberse a diversas causas que no tenían realmente nada que ver con la incontinencia sino más bien con alguna infección en la piel, enfermedad de los órganos genitales o simplemente con que la persona no tenía la capacidad mental para darse cuenta del repudio social que esos actos acarreaban. Como afirmaban Hidalgoy Carpio y Ruíz y Sandoval (1877), en algunas ocasiones estos tocamientos eran mal interpretados:

como suele suceder con algunos imbéciles de toda edad, con ciertos monomaníacos, y con algunos viejos que han llegado a la demencia senil, o si hay alguna enfermedad en ellos que los obliga a llevar con frecuencia las manos a sus partes pudendas o a hacer ciertos movimientos convulsivos al emitir la orina. (p. 8) 
Y precisamente en esas situaciones eran llamados los médicos legistas, pues a ellos les correspondía examinar al individuo para que determinaran si estas acciones eran producto de la malicia, la enfermedad o la falta de capacidad mental y, por lo tanto, si existía delito o no.

\section{b) Sodomía}

Dentro de su diccionario, la sodomía es considerada por Escriche (1863) como el "concúbito entre personas de un mismo sexo" (p. 1475), sin realizar ningún tipo de especificación, mientras que Hidalgo y Carpio, en su Introducción, la describió más bien como un concúbito entre personas del mismo sexo resaltando que se trataba de hombres, lo cual podría deberse a que esta práctica implicaba la penetración.

En el Código penal para el Distrito Federal y Territorio de la Baja California, la sodomía dejó de estar tipificada como delito en la ciudad de México. Sin embargo, como dice Alejandra Palafox (2015), esta continuó criminalizada al insertarse dentro de la amplia categoría de ultrajes a la moral pública o las buenas costumbres (p. 300), Hidalgo y Carpio afirmaba que la sodomía no era un delito como tal si se realizaba en privado, entre adultos y si el acto había sido consensual, pero, sí era perseguida si se efectuaba en espacios públicos, pues entonces era considerada como una falta a la moral pública y las buenas costumbres.

Hidalgo y Carpio asociaba la sodomía con prácticas contra-natura, pues en la sociedad de ese momento lo normal era que se pensaran como relaciones sexuales naturales solamente las sostenidas entre hombres y mujeres debido a la conformación de sus órganos sexuales y sus fines reproductivos. Estas creencias no solamente eran avaladas por la religión, sino también por la biología.

Para establecer la realización del acto sodomítico, en el Compendio, se afirmaba, siguiendo a Tardieu, que los sodomitas tenían tal "configuración de los órganos genitales" que permitía saber si participaban de "esta cópula contranatural" (Hidalgo y Carpio \& Ruíz y Sandoval, 1877, p.12). De esta manera, para reconocer a los que por primera vez se prestaban a la sodomía o a los que eran forzados, los autores añadían que:

[...] en ellos se presentan algunas escoriaciones con rubicundez y relajación del orificio anal, escozor, dolor ardoroso, y una o varias grietas de la membrana mucosa; el individuo tiene dificultad para andar, lo hace con las piernas abiertas, y cuando va a exonerar siente como si el recto quisiera salirse de su lugar. Si ha intervenido la violencia, se encuentran, además, sangre en las inmediaciones del ano y equimósis á su margen (Hidalgo y Carpio \& Ruíz y Sandoval, 1877, p.14-15). 
De este delito quedaban exentos de toda pena los menores de 14 años, aunque fueran ellos los agresores, así mismo los que hubieran sido forzados a realizar actos sodomitas.

En el Compendio (1877), Hidalgo y Carpio y su colega Ruíz y Sandoval consideraban a la sodomía como una plaga y de los que practicaban la sodomía afirmaba que eran "hombres cuyos instintos sexuales se han pervertido hasta el grado de preferir estas relaciones contranaturales a los placeres ordinarios de la Venus" (p. 10), lo cual nos permite ver que, aunque dentro de su práctica médica existía una parte de contenidos eminentemente científicos, también había ideas que reflejaban las creencias culturales de la época y que permeaban este discurso.

Todo lo anterior es parte del discurso y del pensamiento de la época que permeaba en la ciencia a través de sus practicantes, como es el caso de los médicos, por un lado, podemos observar un discurso científico sustentado en la observación de los casos de sodomía y, por otro lado, ideas que pertenecían al ámbito moral- religioso y cultural de la época.

\section{c) Estupro}

Entre los atentados contra el pudor Hidalgo y Carpio mencionaba al estupro y la violación, que eran relacionados con el honor de las personas. El honor era muy importante, era una categoría subjetiva con la que se sopesaban las cualidades morales de las personas, era el mérito, la cualidad, la virtud o la reputación con que contaba un individuo o un grupo social (Twinam, 1991, p.132).

El Estupro, según Escriche (1863) "es la violación de una doncella; y por violación se entiende la corrupción por fuerza" (p. 653). En Introducción (1869), Hidalgo y Carpio menciona que este es clasificado de dos formas: como voluntario y como un acto violento, el primero se da "cuando la mujer se presta al hombre por pura liviandad" y el segundo "cuando interviene la fuerza física o moral, la seducción por engaños, promesas, halagos, respetos, etc., así como la falta de edad, o cierto estado mental que no deje a la mujer comprender su degradación" (p. 59).

Aquí pueden notarse calificativos morales como la "liviandad", que era un comportamiento desenfrenado o concupiscente. En el caso de las mujeres, para detectar el acto impúdico realizado en ellas se les debía someter a un examen minucioso por parte del médico. Para ello era necesaria la revisión de las partes genitales de las mujeres como son los labios grandes, labios pequeños, región urinaria, región genital, carúnculas mitiformes o himeniales, vagina, arco del pubis y el himen. En el caso de los hombres también se debían someter a reconocimiento médico del cuerpo para detectar si habían sido sodomizados.

En cuanto a la falta de edad, recordemos que en los códigos se establecen diferentes penas para el delito de estupro según la edad de la 
persona agraviada. En el artículo 789 del Código penal para el Distrito Federal y Territorio de la Baja California se consideraba que, si el delito era cometido en mayores de 14 años, se castigaba con una multa y con arresto menor, mientras que, si era ejecutado en menores de 12 años, se sancionaba con una multa mayor o con arresto mayor o ambas (Hidalgo y Carpio \& Ruiz y Sandoval, 1877, p.20). Se consideraba en dicho código que se cometía estupro en un menor de 12 años "porque biológicamente no podía todavía disponer de su cuerpo y, por lo tanto, no valía su consentimiento porque carecía de voluntad" (Dzul, 2012).

Hidalgo y Carpio (1869) distinguió el estupro en mujer doncella y el que se comete en la que no lo es, pero es honrada, y el estupro violento, sea o no doncella la mujer (p. 60). También en el Compendio (1877) los autores de éste señalaron con respecto al estupro, que solamente se castigaba como tal el delito ocurrido cuando la mujer era casta y honesta, definida en el Código Penal como aquella que no había tenido cópula ni tocamientos solitarios, así como tampoco con ninguna persona de cualquier sexo (p. 34). Sin embargo, al respecto reconoceron que con la definición anterior era poco probable que se lograra castigar a un hombre, pues este podía alegar que la mujer no era ni casta ni decente en el momento de la violencia, y sugería que era mejor que en el código se dijera: "se presume casta toda mujer que al reconocimiento pericial no diere señales manifiestas de incontinencia" (p. 35).

En este sentido, Hidalgo y Carpio razonaba que las no castas serían "las mujeres que se hubiesen entregado a los excesos del onanismo, las que hubieren consentido la aproximación de un hombre repetidas veces sin consumar la cópula, y aquellas, por último, que hubieren sido desfloradas" (Hidalgo y Carpio \& Ruíz y Sandoval, 1877, p.35). El término desfloración era muy recurrente en la cultura popular del siglo XIX, en la que se hacía referencia a quitar o arrebatar la virginidad de una mujer, lo cual tenía una connotación negativa al ser desfloradas antes de contraer matrimonio. Se reconocía que solamente en estos casos era posible averiguar si la mujer era casta $\mathrm{y}$, para evidenciarlo, se podían hacer pruebas morales o materiales, en las que las morales, siguiendo a Escriche (1863), eran:

[...] la confesión aunque sea extrajudicial; jactancia del acusado, la declaración de testigos; la frecuente conversación y trato de la mujer y el hombre; estando solos en parajes retirados; el ir juntos con un carruaje con las cortinas corridas; el hablar secretamente el hombre a la mujer, especialmente si le ha hecho regalos o escrito cartas amorosas; el visitarla muchas veces durante la noche y aún de día, estando sola; el encerrarse con ella en un cuarto; el abrazarla y hacer cualquiera de aquellos actos que, según las costumbres del país y las circunstancias, inducen sospechas vehementes de trato ilícito (p. 654). 
Es notable que se refiera a "trato ilícito" pues estos comportamientos entre hombres y mujeres eran considerados como inapropiados, pero sobre todo en la mujer, pues en ella recaía el honor, y su conducta era siempre vigilada y sumamente valorada en el ámbito social. La costumbre era que las mujeres tenían que guardar su virginidad, que era atesorada como el bien más preciado con el que ella contaba y, por supuesto, al perderla de manera extramarital era considerado como una pérdida simbólica en el mercado matrimonial (Lorente, 2010, p.185).

Por eso, Hidalgo y Carpio y Ruíz y Sandoval (1877) en cuanto a las pruebas materiales, solamente mencionaron el himen de la mujer, pero eran conscientes de que esto no era una evidencia contundente, pues como lo afirmaban algunos médicos legistas como John Ludwig Casper, el himen no siempre se rompía con el coito (Hidalgo y Carpio \& Ruíz y Sandoval, 1877, p.37). En cambio, cuando había una violación era muy evidente, "porque entonces han de encontrarse contusiones, equimosis, rasguños y aún heridas en los miembros y otras partes del cuerpo, además de lesiones semejantes en los órganos genitales y otras en el cuello o al derredor de la boca y de la nariz que se han hecho al impedir a la mujer que dé voces" (Hidalgo y Carpio \& Ruíz y Sandoval, 1877, p.46).

Por todo lo expuesto anteriormente, se cuidaba al máximo el comportamiento de ellas y, por tal motivo, no es de extrañar que solamente se considerara como víctima de estupro a las mujeres valoradas como decentes, pues las "indecentes” eran señaladas por su dudosa reputación (Carner, 1992, p.95). En este caso, las consideraciones de Hidalgo y Carpio y de su colega Ruíz y Sandoval tenían que ver también con el hecho de que si la mujer era considerada como indecente, entonces era muy difícil que pudiera establecerse un proceso, porque se desestimaría el estupro.

Como las víctimas de estupro no eran obligadas a realizarse el peritaje, esto obstaculizaba el inicio de un proceso penal en contra del estuprador. Y si se lograba establecer un juicio, en todo el proceso había sesgos que comenzaban con el documento escrito que se desprendía del peritaje médico, el cual posteriormente era interpretado (no siempre de la manera más favorable para la denunciante) por los jueces, policías y burócratas (Ferla, 2014, p.3), dando como resultado que en muchas de las ocasiones se desestimaba el delito o se estigmatizaba a la víctima por su comportamiento. Así que con todo lo anterior no es difícil conjeturar que estos delitos fueron poco castigados.

d) violación

Escriche (1863) define la violación como "la violencia que se hace a una mujer para abusar de ella contra su voluntad" (p. 1538). Por su parte, Hidalgo y Carpio y Ruíz y Sandoval en el Compendio consideraron que la violación era el acto que "se comete por medio de la violencia física o moral tiene cópula sin la voluntad de ésta, sea cual fuere su sexo" (Hidalgo y Carpio \& Ruíz y 
Sandoval, 1877, p.44). En esta sí se incluye a hombres y mujeres que forzaran al otro a tener relaciones sexuales. La violencia moral se refería a aquella que se ejercía en los niños, "los cuales por el temor o el respeto a su corruptor, se dejan violar sin oponer la menor resistencia" (Hidalgo y Carpio \& Ruíz y Sandoval, 1877, p.45).

Escriche (1863) afirmaba que este delito era difícil de probar, y que por eso algunos legisladores habían prohibido "admitir quejas de violencia no siendo evidente y real" (p. 1538), Así que para que el proceso fuera admitido en los tribunales las víctimas tenían que realizarse los peritajes médicos en los cuales se evidenciara la violencia y, posteriormente, se determinara el delito (Hidalgo y Carpio \& Ruíz y Sandoval, 1877, p.54).

En el caso de los adultos el doctor Hidalgo decía que se tenían que revisar las lesiones para determinar la violación, pues estas aparecían cuando una mujer había sido sometida por medio de la fuerza física, pero que no siempre era de esta manera, porque también podía ser que hubiera sido forzada moralmente como se explicó en el caso de las niñas. También la violación podía presentarse en los hombres por parte de mujeres, pero el médico menciona que casi siempre se daba en niños de entre 11 y 13 años, quienes después de haber sido seducidos por las mujeres habían sucumbido a tener cópula con ellas (Hidalgo y Carpio \& Ruíz y Sandoval, 1877, p.47).

Por supuesto, en muchas de las ocasiones, las consideraciones para establecer el delito tenían que ver con que las mujeres fueran decentes, pues en caso de que las mujeres fueran sexualmente activas o se dedicaran a la prostitución, no se consideraban como violaciones, aunque fuera evidente que habían sido forzadas. El reconocimiento pericial que se realizaba entra en lo que Foucault llama una relación de saber-poder, pues los médicos decidían sobre el cuerpo de los examinados. En ellos recaía la decisión de si el hecho había sido una violación o no, dependiendo de lo que encontraran en el cuerpo, pero no solamente en este, sino también en la conducta de la víctima. Las vejaciones realizadas en las mujeres, en muchas ocasiones, no tenían un castigo, pues estos dependían en primera instancia de los juicios y prejuicios que los médicos tuvieran, no de la observación clínica. Por lo tanto, fue muy probable que estos actos fueran poco denunciados en la época, ya que las y los que habían sido violentados en su cuerpo, tenían que ir a examinarse con el perito, y lo más lógico es que no quisieran volver a pasar por la vergüenza de que su intimidad fuera expuesta para ser auscultada.

\section{Conclusion}

Los libros de texto o manuales de investigación son considerados de suma importancia en la enseñanza de las ciencias, e imprescindibles en el currículo académico de la formación de los profesionales. Sin embargo, en los manuales que hemos visto no solamente se transmiten conocimientos sino 
creencias e ideología con respecto a los temas que se exponen. Pero más allá de considerar esto como un descrédito de la medicina hay que valorarlo como un desarrollo dentro de un contexto epistémico y cultural. No se podría entender a la ciencia sin el contexto histórico que influye en ella, en la que hay contenidos científicos y otros que son extra-científicos. Recordemos que para el siglo XIX las creencias religiosas del judeo-cristianismo estaban muy presentes. Así que, en el caso de este médico y algunos de sus colegas, por un lado, se encuentraba el individuo que portaba un saber médico, pero por otro, sus apreciaciones sobre los otros individuos dependían de sus juicios morales y creencias culturales.

Con este análisis nos damos cuenta de que las creencias culturales o morales acerca de ciertos temas, eran transmitidas a los estudiantes por medio de los manuales, y aunque es difícil saber con exactitud el grado de influencia que ejercieron, se infiere que tuvieron ciertas repercusiones, dado que eran llevados como libros de texto en la Escuela Nacional de Medicina. Los de Hidalgo y Carpio fueron los únicos manuales nacionales que se publicaron en el siglo XIX. Esto es significativo, puesto que puede dar cuenta de qué tan a la vanguardia intelectual estaban los mexicanos con respecto a la medicina legal en general y también habla de las influencias que consideraron como significativas en su práctica.

Todo este conocimiento fue perfilando a la medicina legal como una disciplina importante para el establecimiento de la verdad frente a la versión que los testigos ofrecían, y frente a lo que los policías lograban recabar en sus pesquisas. Por eso, era importante que se lograran establecer conocimientos científicos acerca de la reacción del cuerpo frente a la violencia, la vida y la muerte.

\section{References:}

1. Carner, F. (1992). "Estereotipos femeninos en el siglo XIX". En C. Ramos Escandón (Ed.). Presencia y transparencia: La mujer mexicana en la Historia de México (95-109). México: El Colegio de México.

2. Carrillo, A. M. \& Saldaña, J. J. (2005). "La enseñanza de la medicina en la Escuela Nacional durante el Porfiriato" . En J. J. Saldaña (Coord.). La Casa de Salomón en México. Estudios sobre la institucionalización de la docencia y la investigación científicas (257271). México: Universidad Nacional Autónoma de México.

3. Código penal para el Distrito Federal y Territorio de la Baja California sobre delitos del fuero común, y para toda la República sobre delitos contra la Federación. (1871). Veracruz: Imprenta del Progreso. Recuperado en: http://cdigital.dgb.uanl.mx/la/1020013105/1020013105.PDF 
4. Dzul Sánchez, J. M. (2012). "Abuso sexual infantil y medicina legal en el ámbito judicial de Yucatán 1875-1925”. Temas Antropológicos, $1,109-141$.

5. Escriche, J. (1863). Diccionario razonado de Legislación y jurisprudencia. París: Librería de Rosa y Bouret.

6. Ferla, L. (2014). "La pericia médico legal como forma de producir la verdad y sus adversarios en los tribunales brasileños de entreguerras". Asclepio. Revista de Historia de la medicina y de la ciencia, 2, 1-13.

7. Flisser, A. (2009). "La medicina en México hacia el siglo XX". Gaceta Médica de México, 4, 353-356.

8. Hidalgo y Carpio L. (1869). Introducción al estudio de la medicina legal. México: Imprenta de Ignacio Escalante y Cía.

9. Hidalgo y Carpio L. \& Ruíz y Sandoval G. (1877). Compendio de medicina legal. Tratado I. México: Imprenta de Ignacio Escalante.

10. Kuhn, T. S. (1979). "Segundas reflexiones acerca de los paradigmas". En F. Suppe (Ed) La estructura de las teorías científicas (509 - 523). Madrid: Editora Nacional.

11. Kuhn, T. S. (1987). La Estructura de las Revoluciones Científicas. México: Fondo de Cultura Económica.

12. Lorente Carpena, A. (2010). "Violación y transgresión. Medicina forense y moral sexual en la España del siglo XIX". Asclepio. Revista de Historia de la medicina y de la ciencia, 1, 277-208.

13. Márquez Estrada, J.W. (2013). "Delitos sexuales y práctica judicial en Colombia: 1870-1900. Los casos de Bolívar, Antioquía y Santander". Palobra, No. 13, pp. 30-48,

14. Martínez Cortés, F. (2003). La medicina científica y el siglo XIX mexicano. México: Secretaría de Educación Pública/ Fondo de Cultura Económica/ Consejo Nacional de Ciencia y Tecnología.

15. Palafox Menegazzi A. (2015). "Sodomía y masculinidad en la Ciudad de México (1821-1870)". Anuario de Estudios Americanos, 1, 289320.

16. Roa Bárcena, R. (1860). Manual razonado de práctica criminal y médico legal forense mexicana. México: Imprenta de Andrade y Escalante.

17. Rodríguez Pérez M. E. (2008). La Escuela Nacional de Medicina 1833-1910. México, UNAM.

18. Rodríguez Pérez M. E. (2009). "Luis Hidalgo y Carpio, editor de la revista la Gaceta Médica de México (1818-1879)". Gaceta Médica de México, 2, 159-166.

19. Sáenz Rangel, J. R. \& García Cantú, A. A. (2018). "Fundamentalismo en el código de 1871. Moral pública y buenas costumbres". Revista Electrónica de Psicología Iztacala, 4, 147-164. 
20. Twinam, A. (1991). "Honor, sexualidad e ilegitimidad en la Hispanoamérica colonial". En A. Lavrin (Coord.). Sexualidad y matrimonio en la América hispánica, siglos XVI-XVIII (127 - 171). México: Consejo Nacional para la Cultura y las Artes-Grijalbo.

21. Watson, K. D. (2011). Forensic Medicine in Western Society. New York: Routledge. 